\title{
Taking stock of Nature's bread and butter
}

VERY occasionally we get our leg pulled about the words on our refereeing form. Our standards call for "topicality, brevity and plausibility". "You'll find this paper seductively plausible", purred an author in a letter of transmittal. "Plausible-yes; correct-no", responded a referee. So we went back in some diffidence to Fowler, who generally gets it right-

'plausible has moved a long way from its original meaning, "deserving of applause". Applied to a person it is always pejorative; a plausible man is one who obtains a credence he does not deserve. Applied to an argument the word has not travelled so far on the downward path: it may still be used of one that commends itself, though speculative.'

Continue to send us plausible papers. We will do our best not to send them to plausible referees.

- It is no doubt foolish to boast of the turn-round time for manuscripts, but since it forms the basis on which many scientists decide where to publish, here goes. Once a manuscript has been accepted, it will, on average be published within six weeks.

Statistics on the refereeing process are far more variable, of course, as it may take anything from a week upwards to satisfy ourselves and a referee that a paper should or should not be published. Not all papers go to referees. Some of those submitted seem to us more obviously suited to a specialised journal; and after taking appropriate opinions around the office -and often outside-we return such manuscripts as soon as possible. There is little point in seeking a referee's opinion and only then over-ruling it with our own opinion.

Of the remaining manuscripts, we seek a referee's vicws on all but a tiny fraction. The tiny fraction are not, as is widely believed, those written by very eminent men, but papers on matters where the facts are indisputable and delay would be positively detrimental to the community.

Some authors feel that sending a paper to a distinguished scientist for him to transmit does some good. It doesn't-it only profits the Post Office.

- One of the greatest problems encountered by subeditors is that of ambiguity. This is exceptionally acute in a journal in which more than half the readers and many of the authors do not have English as their first language. English is undoubtedly an organic language capable of great flexibility and subtlety through the ease with which it handles nouns as adjectives, absorbs new words, possesses many words meaning almost the same thing and so on. Asset though this is, particularly in the spoken language, it does lead to difficulties for the reader-and not only the reader to whom English is a second language.

It is impossible to set down guidelines; ambiguities follow no rulebook. But here are some which may give some idea of the subtleties which readers are sometimes asked to unravel.

Jones is a solid state physicist (or soft rock geologist).

The equipment has provided extensive trouble free operation.

Smith's paper suggests a new concept (to Smith or to the author?)

Since Robinson made the observations, we have confidence in the theory.

Brown's work appeared to resolve the difficulty.

We shall hopefully repeat this work within a month.

The solution boiled momentarily.

(These last two demonstrate that the generation of ambiguous euphemisms for 'I hope' and 'in a moment' has effectively eliminated two words from the language.)

Some of these examples seem trifling to the English speaker; but the test we try to apply (not always with success) is whether the writing would be clear not only to someone not having English as a first language, but also to someone from a remote discipline reading out of curiosity.

- It is always tricky to know what references are really necessary; to the extent that we attempt at one and the same time to carry large numbers of short scientific reports and also to have them widely accessible we cannot avoid some conflict over the amount of referencing. But on the whole, we prefer relatively few references because anyone who finds interest in a paper outside his own field is presumably going to look and talk further. Particularly vulnerable to the subeditor's pen are sentences that declare: "There has recently been great interest in this subject ${ }^{1-11}$ and much work ${ }^{12-25}$ is at present in progress".

- Many people secretly fancy themselves as advertising copywriters and would relish the opportunity to string together compelling but honest words to persuade others to buy cars, read books or (dare we say) to drink a certain brew or smoke a certain cigarette. And yet given an opportunity for self-advertisement, most scientists shy away from compelling but honest words with which to introduce their papers.

Nature has always avoided a summary at the beginning of letters partly for reasons of space, partly in an attempt to retain a certain directness in the reporting of early and often tentative results. But this should not inhibit anyone from writing a short and forthright first paragraph, capable of being understood by almost anyone. On occasions our sub-editors attempt to do this themselves for authors, but the response is often: "Well I didn't quite mean that". Which might, just once in a while, not stem entirely from our dim-wittedness but conceivably from a touch of opacity in the paper itself. 